\title{
ADAPTACIÓN GINEMATOGRÁFICA DE COMO AGUA PARA CHOCOLATE
}

\author{
Lidia MARTÍ BARCHÍN
}

Universidad de Alicante

\section{RESUMEN}

Como agua para chocolate es una novela de Laura Esquivel, publicada en 1989. Esta historia obtuvo un éxito abrumador, lo que llevó a que Alfonso Arau realizara, de una manera brillante, una adaptación cinematográfica en el año 1992. En este artículo vamos a analizar los procedimientos más destacados que se utilizaron para llevar a cabo el trasvase de la novela a la película. Del mismo modo, destacaremos los reconocimientos que ha obtenido esta producción a nivel nacional e internacional, hecho que influye de forma positiva en su popularidad.

Palabras clave: Adaptación cinematográfica, Alfonso Arau, Laura Esquivel, premios, producción.

\section{ABSTRACT}

Como agua para chocolate is the most important novel of Laura Esquivel, which was published in 1989. This story obtained an overwhelming exit. For that reason Alfonso Arau decided to make a brilliant film adaptation in 1992. In this article we will analyse the most important methods that were used to produce the film. We will also highlight the different awards that the film has obtained nationally and internationally.

Keywords: Film adaptation, Alfonso Arau, Laura Esquivel, awards, production.

\section{INTRODUCCIÓN}

En el presente artículo vamos a realizar un análisis de la adaptación cinematográfica de la novela Como agua para chocolate. El título se corresponde con la primera publicación de Laura Esquivel en 1989. La película se estrenó en el año 1992 y fue producida por Alfonso Arau. Es muy interesante la gran semejanza que existe entre la novela y la película y esto se debe, fundamentalmente, a que la guionista de la película fue Laura Esquivel, que había comenzado su carrera en la escritura realizando guiones cinematográficos. 
En primer lugar, vamos a prestar atención a las características y al argumento de la novela que escribió la autora mexicana en torno a la historia de Tita. A continuación, nos centraremos en la adaptación cinematográfica. Para ello, haremos alusión a la participación de Laura Esquivel como guionista y a la producción y dirección que lleva a cabo su marido, Alfonso Arau. Más adelante, estudiaremos el papel que desempeñaron los actores, haciendo hincapié en la idoneidad de estos para interpretar los papeles que tenían por delante. Del mismo modo, pasaremos a analizar los procedimientos que se emplearon en esta adaptación cinematográfica, basándonos en las escenas que se han suprimido o que han cambiado con respecto a la escena recreada en la novela, en la música y en los efectos de sonidos producidos, en el vestuario y en su capacidad para retrotraernos a la época de la revolución mexicana y, por último, hablaremos de la voz en off, que coincide con la narradora en tercera persona de la novela y que ha sido un acierto dejar en la adaptación cinematográfica.

En definitiva, nos encontramos ante una adaptación que tuvo una buenísima acogida, tanto o mejor que la novela homónima. Muestra de este éxito son los diferentes premios y nominaciones nacionales e internacionales de las que hablaremos posteriormente.

\section{LA NOVELA DE LAURA ESQUIVEL}

Como agua para chocolate fue la primera novela de la autora Laura Esquivel. Se trata de una de las obras más conocidas del movimiento literario del realismo mágico. Supuso un éxito en la historia de la literatura, llegando a traducirse a más de treinta idiomas y a recibir algunos premios interesantes, como el galardón ABBY (American Bookseller Book of the Year) al mejor libro, otorgado por American Booksellers Asociation.

Por lo que respecta al argumento de la obra, Laura Esquivel se centró por completo en la historia de la familia de la Garza. Esta familia está integrada, principalmente, por mujeres. En la localidad de Piedras Negras, Estado de Coahuila, México, conviven en un rancho una madre y sus tres hijas. Asistimos a la descripción de la vida de Tita, la hija menor de Mamá Elena, que, junto a sus dos hermanas, Rosaura y Gertrudis, soporta la tirana autoridad de su madre. El destino de Tita queda marcado desde el momento de su nacimiento. Mamá Elena da a luz en la cocina, el padre de Tita fallece a los pocos días de su nacimiento, por lo que la niña queda a cargo de Nacha, la cocinera del rancho, quien se encargará de alimentarla y de darle todo su cariño.

A medida que Tita se va convirtiendo en una mujer adulta, se da cuenta de que su vida se limita a obedecer las órdenes de su madre, entre las que se incluye su obligación de no casarse y no formar una familia porque, al ser la hija pequeña, debe estar siempre al cuidado de su madre, dada una tradición familiar que Tita considera absurda. No obstante, esta prohibición no impide que la protagonista se enamore de Pedro e intente hacer que Mamá Elena cambie de opinión. Finalmente, su madre se niega rotundamente a la boda entre Tita y Pedro, por lo que este decide casarse con Rosaura para vivir en el rancho cerca de su verdadero amor. El día de la boda de Pedro y Rosaura coincide con el fallecimiento de Nacha, acontecimiento que ligará a Tita a los fogones del rancho.

Una vez que Tita ha ocupado su nuevo espacio en la casa, la cocina, inventa una nueva forma de comunicación con Pedro a través de la comida. Todo sucede cuando Pedro le regala unas rosas con motivo de su primer aniversario como cocinera y Tita escucha la voz de Nacha, que le transmite la receta de las codornices en pétalos de rosa. A la hora de degustar este plato, todos comienzan a sentir sensaciones extrañas, excepto Mamá Elena, 
que solo nota la comida salada. Es en la figura de Gertrudis en quien se personifica ese amor prohibido que existe entre Tita y Pedro. Al probar las codornices, Gertrudis siente un calor abrasador y sale corriendo al exterior del rancho para darse una ducha. Sin embargo, se da cuenta de que está incendiando todo su alrededor. Se marcha corriendo desnuda por el campo y, finalmente, sube a lomos del caballo de Juan Alejandrez, el hombre del que se había enamorado y que había llegado al rancho siguiendo un olor irremediable a rosas.

Esta huida de Gertrudis del rancho supone la liberación de la hija mayor de Mamá Elena de su régimen autoritario. No obstante, a su cargo sigue quedando Tita, la hija pequeña y soltera, quien decidirá continuar cocinando las recetas que Nacha le va concediendo desde el más allá e, incluso, inventa algunas nuevas para que su relación con Pedro no decaiga. A pesar de que ha encontrado una vía de escape en la cocina, su vida en el rancho se hace del todo insoportable cuando Pedro se marcha con Rosaura y su hijo a Texas. Es en ese lugar donde el hijo de Pedro fallece y, al recibir la noticia, Tita reprocha a su madre la muerte de su sobrino, pues conoce que el niño no podía alimentarse porque todo le sentaba mal. Cuando Roberto estaba en el rancho, Tita lo amamantaba de forma milagrosa, pues de sus pechos brotaba leche sin que ella hubiese concebido ningún hijo. Tras conocer la nueva de la muerte de su sobrino, Tita entra en una especie de locura provocada por la asfixiante situación que vive en el rancho de Mamá Elena.

Después de este episodio, el doctor Brown se lleva a Tita a su casa y con él comenzará una relación muy importante, ya que ambos personajes llegan a pensar en boda. Sin embargo, la muerte de Mamá Elena hace que Tita, Rosaura y Pedro regresen al rancho. Entonces, el amor entre Tita y Pedro se retoma con más fuerza que nunca y, como consecuencia, el compromiso entre Tita y el doctor Brown se rompe. Ambos amantes comienzan una relación a espaldas de Rosaura, quien ya ha dado a luz a su hija Esperanza y pretende que continúe con esa absurda tradición familiar de no casarse ni tener hijos para quedar al cargo de su madre, a lo que Tita se opone radicalmente $y$, junto a Pedro, se enfrentarán duramente a Rosaura.

Finalmente, Rosaura fallece debido a una enfermedad digestiva y Esperanza tiene el camino libre para casarse con el hijo del doctor Brown. Una vez que la sobrina de Tita se ha marchado del rancho, la protagonista tiene la ocasión de disfrutar de su amor con Pedro sin que haya nadie de por medio. Sin embargo, este hecho tendrá unas consecuencias terribles, ya que entre ambos se desata una pasión desenfrenada que les conducirá a la muerte.

En referencia al marco en el que sucede la acción, los lectores asistimos a la descripción de un mundo mágico, en el que suceden acontecimientos maravillosos que los protagonistas toman con total naturalidad. Esto es una característica principal de las obras mágico-realistas. En la novela estos efectos se consiguen con las palabras, pues Laura Esquivel, a través del uso de la tercera persona y de la intensa y minuciosa descripción que realiza, consigue que el lector entre de lleno en ese mundo mágico que intenta sugerir. Está claro que, para que esto suceda, el lector debe tener fe en el relato, dejarse llevar e imaginar todo lo que el autor le está describiendo.

\section{ADAPTACIÓN CINEMATOGRÁFICA}

Como ya comentábamos en el apartado anterior, los relatos mágico-realistas pretenden mostrar una realidad maravillosa y mágica y, para ello, los autores se valen del uso de la palabra. No obstante, cuando se piensa en una adaptación cinematográfica de una obra del 
realismo mágico parece que estos elementos maravillosos pueden suponer un problema. Realmente, uno de los primeros aspectos en los que debe pensar el productor de una adaptación de este tipo es en el procedimiento que va a seguir a la hora de suscitar la magia requerida.

En el caso de Como agua para chocolate asistimos a una adaptación cinematográfica de gran calidad y uno de los principales aciertos fue la participación de Laura Esquivel como guionista, además de los aspectos que explicaremos más adelante, como la elección de los actores, el vestuario, la música utilizada y la voz en off que va guiando al espectador en la historia que está visualizando.

Antes de pasar a analizar los procedimientos empleados en la adaptación cinematográfica, es necesario recordar que el discurso empleado en el cine, por su naturaleza, ha sido ampliamente estudiado, ya que despierta un gran interés entre la crítica. Este lenguaje, diferente al que encontramos en la novela, une distintos códigos que interactúan entre sí dando vida al producto audiovisual (Patou-Patucchi, 2012: 21-27). Además, cabe recordar que el lenguaje cinematográfico se asemeja mucho al lenguaje oral, pero tiene algunas diferencias interesantes. Por un lado, el lenguaje cinematográfico tiene menos repeticiones $y$, por tanto, es más uniforme que el lenguaje oral. Por otro lado, los turnos de habla duran más que en la conversación, lo que lleva a que en algunas películas podamos observar verdaderos monólogos de los protagonistas que, en la mayoría de las ocasiones, tienen una finalidad concreta, como la de conocer mejor al personaje o ahondar en su personalidad de forma directa y personal (Briz, 2000: 9-32).

\subsection{Laura Esquivel, guionista, y Alfonso Arau, director: premios recibidos ${ }^{1}$}

Como ya hemos comentado, Laura Esquivel es la autora de Como agua para chocolate. A pesar de que se trata de una novela, los inicios de Esquivel en la escritura estuvieron relacionados con la redacción de guiones cinematográficos. De hecho, en el año 1985, cuatro años antes de su gran éxito novelístico, estuvo nominada al premio Ariel por el guion de Chido One, el Tacos de Oro. Por esta razón, Alfonso Arau, director y productor de la película, le confió la redacción del guion que, como podemos atisbar en la película, no dista mucho de las palabras que encontramos en la novela (Baluet y Chesnokova, 2013: 215).

Por lo que respecta a la dirección y producción de la película, esta estuvo en manos de Alfonso Arau, un reconocido director, productor, actor y cantante mexicano. Como director, obtuvo un gran reconocimiento por la película de la que estamos hablando, por la que estuvo nominado al Globo de Oro. Además, obtuvo el premio al mejor director por la Asociación de Cronistas de Espectáculos de Nueva York en 1993 por la misma película, el premio Hugo de Oro por mejor guion y Premio de la Audiencia en el Festival Internacional de Cine de Chicago en 1992, el premio de la Audiencia por la muestra de cine mexicano en 1992 y el premio Ariel por mejor película, dirección, dirección de arte y ambientación en 1992, además de otras nominaciones importantes.

En referencia a España, Como agua para chocolate fue una de las películas propuestas para la obtención del premio Goya a la mejor película extranjera de habla hispana en 1993.

1 Los datos de la ficha técnica y de los premios otorgados a la película los proporciona Estela Rosales en la página de cine mexicano, ITESM: https://web.archive.org/web/20050909062452/http://cinemexicano.mty. itesm.mx/peliculas/chocolate.htm. 
Por esta razón, nos damos cuenta de que la película supuso un éxito no solo a nivel nacional, sino a nivel mundial, consiguiendo que la historia de Tita llegara a muchas más personas a través del medio audiovisual.

\subsection{Selección de los actores}

Uno de los aspectos que conviene destacar de toda película o adaptación cinematográfica es el reparto de actores. En este caso, nos encontramos ante la presencia de intérpretes poco conocidos hasta el momento del estreno de la película, como es el caso de la protagonista Tita, interpretada por Lumi Cavazos. Este papel en Como agua para chocolate hizo que consiguiera el premio a mejor actriz en el Tokyo International Film Festival y en el Festival de Gramado de Brasil. Además, se dio a conocer en la industria cinematográfica estadounidense, lo que le concedió la posibilidad de trabajar en ella. Sin embargo, el reparto de la película también cuenta con la presencia de actores más conocidos, como Ada Carrasco, que interpreta el papel de Nacha, la cocinera, pero no obtuvo reconocimientos o premios por su interpretación.

Del mismo modo, es interesante resaltar la nacionalidad de los actores que participaron en el proyecto. Tanto Lumi Cavazos, como Ada Carrasco, las dos actrices mencionadas anteriormente, son de nacionalidad mexicana. No obstante, es interesante la elección del Marco Leonardi para interpretar el papel de Pedro Muzquiz, ya que es australiano, por lo que se hizo necesaria la participación de un actor de doblaje, que fue Guillermo Sauceda.

Asimismo, cabe mencionar la adecuación de cada actor al personaje que le ha sido asignado. Si nos centramos en el personaje de Tita, la elección de Lumi Cavazos es muy acertada, ya que nos transmite esa imagen de chica que acaba de llegar a la adolescencia y madurez. Además, su interpretación es muy interesante, pues sabe reflejar en su rostro la bondad e inocencia que caracteriza a Tita, pero también su rechazo a la represión que vive en el rancho. Por su parte, destaca el personaje de Mamá Elena, encarnado por Regina Torné. Esta interpretación le otorgó el premio Ariel a la mejor actriz en 1992. Por lo que respecta al personaje de Nacha, es muy curiosa la caracterización del personaje porque representa a la perfección ese papel de anciana que cuida de la familia. Más interesante aún es el personaje de Chencha, interpretado por Pilar Aranda, a quien se le introducen ciertas alteraciones en el lenguaje que tienen que ver con una forma muy particular de hablar. Por último, cabría destacar al Doctor Brown, encarnado por Mario Iván Martínez que, a pesar de ser de origen mexicano, se vio en la obligación de interpretar su personaje con un acento estadounidense, dado que su personaje proviene de este país, reto que consigue a la perfección.

En consecuencia, dadas las características de los actores y la forma que tuvieron de adecuarse a sus personajes, queda claro que este fue uno de los puntos fuertes de la adaptación cinematográfica. Además, los numerosos reconocimientos que han obtenido los intérpretes por su actuación en Como agua para chocolate, tanto con premios como con nominaciones, dan cuenta de este hecho.

\subsection{Procedimientos empleados en la adaptación}

A la hora de realizar una adaptación cinematográfica, hay que seguir una serie de procedimientos. Debemos tener en cuenta que el cine se vale de un lenguaje completamente diferente del que emplea la novela. Por ejemplo, si queremos expresar el sentimiento de un 
personaje, la novela necesitará una mayor descripción, tanto del entorno, como del físico del protagonista, como de sus sentimientos, mientras que en el cine bastaría con acercar la cámara a la cara del actor y que esta sugiera ese sentimiento que se quiere transmitir a los espectadores. Por tanto, somos conscientes de que, muchas veces, hay que hacer algunos cambios en la forma de narrar la historia para que se adecue a su nuevo lenguaje, el cinematográfico. No obstante, estos cambios no quieren decir que la historia haya perdido valor y, en consecuencia, no sería oportuno repetir la famosa sentencia "el libro es mejor que la película".

Además, la película muestra una estética muy cuidada, de ahí que la iluminación y la fotografía sean fundamentales. Por lo que respecta a la luz y a los colores, observamos unas tonalidades anaranjadas, una luz muy cálida, que envuelven las escenas con una gran sensualidad y ternura. El filme está ambientado de forma brillante, la música elegida, por ejemplo, también forma parte de la época en la que tiene lugar la acción.

Otro elemento que resulta característico para la película es el hecho de que la comida se convierte en el hilo argumental de la historia. Los platillos que Tita prepara son fundamentales para entender la historia, por lo que se toman planos de estas recetas de forma muy detallada. De no haber sido así, se habría perdido una gran parte del significado que tiene la novela.

\subsubsection{Escenas suprimidas y cambios sugeridos}

Por lo que respecta a las escenas suprimidas en la película, debemos recordar la idea tratada anteriormente y es que el lenguaje cinematográfico es capaz de transmitir la misma idea de una forma más breve que la novela, por ejemplo. Tal y como afirma Marcel Martin, "el cineasta, capaz de mostrar todo y conociendo el formidable coeficiente de realidad que impregna a todo lo que aparece en la pantalla, puede recurrir a la alusión y hacerse comprender en media lengua" (Martin, 2005: 83).

Siguiendo esta línea, si nos damos cuenta, uno de los personajes de la novela no aparece en el filme. Se trata de Luz del Amanecer, abuela del doctor Brown. Esto se debe a que las escenas en las que aparece Luz del Amanecer en la novela no son determinantes en el desarrollo de la trama, por lo que se tomó la decisión de suprimirlas. Sin embargo, no desaparece del todo este personaje, ya que el doctor Brown mantiene las constantes alusiones a las enseñanzas que le proporcionó su abuela.

Otra de las características interesantes es que en la película se conservan las alusiones al pasado de Mamá Elena. Aunque no se haga de la misma forma que en la novela, somos conscientes de que el marido de Mamá Elena muere a causa de un infarto provocado por la noticia de que Gertrudis no es su hija. También vemos a Tita escondida en el armario de su madre con un cofre entre las manos, el mismo cofre que, cuando muere su madre, consigue abrir y, de este modo, descubrir toda la verdad. Como ya hemos comentado, aunque algunas escenas o datos de los amores de Mamá Elena se hayan suprimido, no son necesarios para conocer el origen negro de Gertrudis y, por tanto, la explicación a que su hija sea negra.

Siguiendo con Gertrudis, en la película da a luz a una hija negra, lo que hace que su marido desconfíe de ella, por lo que Tita se ve obligada a contar los secretos de Mamá Elena. La única diferencia que encontramos en este caso con respecto a la novela es que, en el filme, Gertrudis tiene una hija y en la novela da a luz un hijo varón. 


\subsubsection{Música}

En referencia a la música, resulta ser una parte fundamental para las adaptaciones cinematográficas y para cualquier película en general. En este caso, la música estuvo a cargo del guitarrista cubano Leo Brouwer. Además, en el filme podemos escuchar canciones muy conocidas en la cultura mexicana, como "Estrellita marinera" o "Mi querido capitán", interpretadas por el Trío de los Morales, un grupo de música principal para el folclore mexicano. Por ejemplo, vemos que la música es un elemento característico de cualquier reunión familiar. En las bodas celebradas en Como agua para chocolate, la música está presente y es, junto con la comida, la encargada de animar la fiesta y de agradar a los invitados.

Del mismo modo, los efectos sonoros son realmente importantes para la película. Como ya hemos dicho, se trata de una historia mágico-realista y la música y los efectos sonoros cobran un papel fundamental a la hora de suscitar lo maravilloso. Lo mismo ocurre con las películas de terror, ya que se utilizan unos sonidos que nos ponen en alerta y nos avisan de que algo va a pasar. En Como agua para chocolate, asistimos a la presencia sobrenatural de Mamá Elena una vez que ha fallecido. Esta presencia no solo nos indica que es un elemento sobrenatural, sino que también nos deja claro que es una aparición premonitoria de que algo malo va a suceder. Por tanto, si analizamos los efectos sonoros, entenderemos que son fundamentales para introducir al espectador en ese mundo de maravilla y de premonición del que se trata. No obstante, los sonidos son distintos cuando se trata de la aparición sobrenatural de Nacha, ya que son mucho más relajados. Esto se debe a las connotaciones que tienen ambos personajes. Por un lado, Mamá Elena significa la opresión y la represión para Tita. Por tanto, su aparición una vez que ha muerto no puede representar otra cosa que la intención de culpabilizar a Tita por sus acciones y, de este modo, seguir controlándola desde el más allá. Por otro lado, Nacha siempre ha realizado el papel de verdadera madre para Tita. Por esta razón, su aparición como un fantasma no tiene un significado negativo, sino todo lo contrario, pues es quien le va marcando el camino que debe seguir la protagonista.

En definitiva, la música y los efectos producidos con el sonido son primordiales en las películas para guiar adecuadamente a los espectadores a lo largo de la historia que se está narrando y suscitar las emociones adecuadas en cada momento.

\subsubsection{Vestuario}

Por su parte, el vestuario es fundamental a la hora de caracterizar a los personajes. Si nos fijamos, al leer una novela, nos imaginamos a los personajes y eso incluye imaginar su forma de vestir. Sin embargo, cuando vemos una película, no tenemos que pensar en estos elementos porque ya nos vienen dados, es decir, ya hay un encargado de realizar tal función. En este caso, el vestuario estuvo a cargo de Carlos Brown.

Como bien es lógico, cada personaje utiliza un vestuario adecuado a su edad o posición social. Los hombres más importantes de la historia, Pedro y John Brown, aparecen engalanados con trajes. Mamá Elena, una vez que ha muerto su marido, utiliza ropa de color oscuro, símbolo de luto. No obstante, también aparece con otros atuendos de color oscuro - blanco. Los trajes que lucen las mujeres de la Garza son de clase media-alta y se puede observar en los tejidos, los colores o la confección. Solamente el caso de Tita es el más llamativo, ya que no viste como su hermana Rosaura, sino que utiliza una ropa que podría 
asemejarse a la que llevan las mujeres de baja clase social. Quizás este hecho se deba a que Tita es la cocinera del rancho. Lo mismo ocurre con los peinados. Tanto Mamá Elena como Rosaura llevan recogidos prominentes y muy llamativos, pero Tita se conforma con llevar el pelo suelto o algún semirrecogido muy sencillo.

Esta situación cambia por completo cuando hay una fiesta. En ella, todas las mujeres de la casa sacan sus mejores galas, ya que la opinión pública es muy importante. Esta realidad no es aplicable a Nacha y a Chencha, ya que son de clase social baja y, al dedicarse a la cocina, cuidado y servicio, deben llevar ropa más discreta.

\subsubsection{Voz en off}

Uno de los procedimientos más interesantes de Como agua para chocolate es la voz en off. Mediante esta técnica, los productores consiguen introducir al espectador en el mundo mágico que se narra en la novela. A pesar de visualizar los elementos sobrenaturales, el espectador no puede reconocer lo que está viendo como parte de una realidad maravillosa, por lo que se hace necesario el uso de la palabra. Para ello, es muy útil la voz en off, que coincide con la narradora en tercera persona de la novela, es decir, con la sobrina nieta de Tita que, además, la podemos ver en la primera y última escena. Un ejemplo interesante de este procedimiento son los primeros momentos de la película, en los que la guionista decide mantener la narración de la sobrina nieta de Tita en lugar de mostrar la evolución de la protagonista de forma meramente visual. Además, la última escena es muy importante, ya que podemos ver a la narradora junto a Esperanza y a Tita, como miembros de su pasado y haciendo hincapié en la trascendencia de esa historia que acaba de relatar.

Asimismo, cabe destacar aquellas escenas en las que la palabra no se hace necesaria, como los encuentros sexuales que viven Tita y Pedro. En este caso, lo visual tiene un gran poder y un único beso y algún sonido son suficientes para sugerir a los espectadores cómo acaba el encuentro entre ambos protagonistas. Esta misma situación se repite al final de la película, cuando los dos amantes llegan a autodestruirse a causa de sus emociones. En la escena vemos cómo Pedro fallece y cómo Tita se quita la vida para estar con él. Finalmente, ambos encuentran una luz que los lleva a su verdadero lugar en el mundo. Toda esta realidad no se cuenta mediante palabras, sino que la imagen es suficiente para que el espectador comprenda lo que ocurre en la escena.

Por tanto, debemos destacar que la presencia de la voz en off se hace necesaria en algunas ocasiones, pero en otras la imagen es suficiente. En el caso de Como agua para chocolate ha sido un acierto mantener la presencia de la voz en off de la misma manera que aparece la narradora en tercera persona de la novela. Este éxito se debe, en gran parte, a la formación que tiene Laura Esquivel como guionista. Es necesario recordar que su contacto con el cine se produjo mucho antes de lo que lo hizo con la novela. En consecuencia, es una escritora con una formación cinematográfica indudable y, probablemente, a la hora de escribir Como agua para chocolate tuviera influencias de la escritura de guiones o que, incluso, pensara en cómo se podría realizar una película de esta novela. Es por esta razón que observamos tantos parecidos entre la novela y la película, ya que el filme es muy fiel al relato y las palabras que utiliza son prácticamente las mismas. 


\section{CONCLUSIONES}

Para concluir, sería necesario recordar que la cercanía entre libro y película se debe, en primer lugar, a la estructura puramente cinematográfica que Laura Esquivel da a la novela. La novela, en definitiva, parece haberse creado para ser representada en la gran pantalla (Garzelli, 2013: 261).

Anteriormente, hemos señalado la importancia de que se trate de una historia mágicorealista, por lo que la película no podría haberse quedado atrás en el uso de elementos que introduzcan al espectador dentro del mundo maravilloso. Es por esta razón que la adaptación está dotada de elementos del realismo mágico como, por ejemplo, las distintas apariciones de Mamá Elena o las escenas sobrenaturales que se introducen. Como bien nos hemos podido dar cuenta, estas escenas no alteran el ritmo normal del relato o de la película.

Del mismo modo, podemos atisbar que Como agua para chocolate fue una película que trascendió las barreras nacionales, se tradujo a muchos idiomas y, por tanto, llegó a un gran número de países de todo el mundo. Uno de los ejemplos es España, donde la película estuvo nominada al premio Goya a la mejor película extranjera de habla hispana en 1993. Aunque no ganara el premio, la sola nominación a él supone un reconocimiento a la gran acogida que tuvo en España la película. Además, el éxito de ella no se queda solamente en los años noventa, sino que llega hasta nuestros días prácticamente. En 2017 el periódico El Mundo recogía la noticia de que Endemol Shine Studios había adquirido los derechos de la novela y desarrollaría una serie en inglés, con previsiones de traducirla a otros idiomas (Elidrissi, 2017).

Para finalizar, cabría destacar la buena predisposición de la autora de la novela a la hora de distintas productoras se interesen por la historia de Tita para crear nuevas adaptaciones. Ella misma colaboró con Alfonso Arau, su marido y productor de la película de 1992, y también mostró su alegría por la adaptación que se anunció en 2017, afirmando sentirse muy alegre de que su novela llegue a la pequeña pantalla gracias a una compañía que se fija mucho en la calidad y el contenido de las obras que adapta y que ofrece a sus usuarios (Elidrissi, 2017).

\section{BIBLIOGRAFÍA}

Arau, Alfonso, Como agua para chocolate, México, 1992.

BALUET, Nicolás y CHESNOKOVA, Olga, (2013): "Como agua para chocolate de Laura Esquivel: recepción crítica y traductología" e-scrita (Nilopolls), vol. 4, n 1, pp. 213-230.

BRIZ, Antonio (2000): "Turno y alternancia de turno en la conversacion", Revista Argentina de Lingüística, n¹6, pp: 9-32.

ELIDRISSI, Fátima (2017): "Como agua para chocolate será una franquicia televisiva global", El Mundo, 10 de marzo de 2017, versión on-line. Disponible en: https://www.elmundo.es/tel evision/2017/03/10/58bda81 be2704ea63e8b45df.html (fecha de consulta: 18/06/2019).

ESQUIVEL, Laura (1994): Como agua para chocolate, Barcelona, Salat.

GARZELLI, Beatrice (2004): "El discurso cinematográfico entre traducción intersemiótica, doblaje y subtitulación Como agua para chocolate (1992) y Mar adentro (2004)", Cuadernos AISPI: Estudios de lenguas y literaturas hispánicas, n², pp. 257-276. 
MARTIN, Marcel (2005): El lenguaje del cine, Barcelona, Gedisa, 2005.

PATOU-PATUCCHI, Sergio (2012): "The viewer/learner of audiovisual language", Filmtranslation from East to West. Dubbing, subtitling and didactic practice, eds. Claudia Buffagni; Beatrice Garzelli, Bern, Peter Lang, pp: 21-27. 